3

\title{
Intersensor Calibration between F13 SSMI and F17 SSMIS \\ for Global Sea Ice Data Records
}

Donald J. Cavalieri, Claire L. Parkinson, Nicolo DiGirolamo, and Alvaro Ivanoff

\begin{abstract}
An intercalibration between F13 Special Sensor Microwave Imager (SSMI) and F17 Special Sensor Microwave Imager Sounder (SSMIS) sea ice extents and areas for a full year of overlap was undertaken preparatory to extending the 1979-2007 NASA Goddard Space Flight Center (GSFC) NASA Team algorithm time series of global sea ice extents and areas. The 19792007 time series was created from Scanning Multichannel Microwave Radiometer (SMMR) and SSMI data. After intercalibration, the yearly mean F17 and F13 difference in Northern Hemisphere sea ice extents is $-0.0156 \%$, with a standard deviation of the differences of $0.6204 \%$, and the yearly mean difference in Northern Hemisphere sea ice areas is $0.5433 \%$, with a standard deviation of $0.3519 \%$. For the Southern Hemisphere, the yearly mean difference in sea ice extents is $0.0304 \% \pm 0.4880 \%$, and the mean difference in sea ice areas is $0.1550 \% \pm 0.3753 \%$.

This F13/F17 intercalibration enables the extension of the 28-year 1979-2007 SMMR/SSMI sea ice time series for as long as there are stable F17 SSMIS brightness temperatures available.
\end{abstract}




\section{Introduction}

Earth observing satellites have proven to be extremely valuable for monitoring our changing planet (King et al., 2007) and for serving as the basis of producing long-term geophysical data records (Gurney et al., 1993). The utility of these long-term data records depends on the generation of a consistent set of measurements made from different sensors on different satellites over many years. One of the longest such data records is that for sea ice, which spans $30+$ years and is distributed by the National Snow and Ice Data Center (Cavalieri et al., 1996; updated 2008). The approach followed in the generation of the NASA Goddard Space Flight Center (GSFC) NASA Team (NT) algorithm sea ice data record was to match the various data sets at the sea ice product level rather than at the satellite radiance level (Cavalieri et al., 1999). This approach has also been followed by the majority of end-users in the generation of long-term time series of geophysical variables, as for example, snow water equivalent (Derksen et al., 2003). The rationale for this approach stems from the complications that arise when trying to match brightness temperatures for scenes partially covered with water and has been discussed in detail by Zabel and Jezek (1994).

The existing intercalibrated NASA GSFC sea ice data record spans the period from October 26, 1978 through December 31, 2007 and is based on data obtained from the NASA Nimbus 7 Scanning Multichannel Microwave Radiometer (SMMR) (October 26, 1978 through August 20, 1987), the DMSP F8 Special Sensor Microwave Imager (SSMI) (July 9, 1987 through December 18, 1991), the DMSP F11 SSMI (December 3, 1991 through January 12, 1998), and the DMSP F13 SSMI (May 3, 1995 through December 31, 2007). The DMSP F13 SSMI started to degrade in 2008. A new sensor called the Special Sensor Microwave Imager Sounder (SSMIS) 
1 combined the SSMI conically scanning capability with high-frequency sounding channels and

2 was first launched on the DMSP F16 satellite in 2003 (Kunkee et al., 2008), with a second

3 SSMIS launched in 2006 on DMSP F17. The SSMIS on the DMSP F17 satellite has an

4 ascending node crossing time closer to the DMSP F13 SSMI than does the F16 SSMIS, and

5 hence the F17 SSMIS was selected to extend the sea ice time series by W. Meier of the National

6 Snow and Ice Data Center (NSIDC) in collaboration with D. Cavalieri and C. Parkinson of

7 NASA GSFC. The F17 SSMIS data extend from December 14, 2006 to the present, and we use

8 the full year 2007 of data overlap with the F13 SSMI to intercalibrate the sea ice time series from

9 the F13 SSMI and the F17 SSMIS.

11 The source of the calibrated F17 SSMIS brightness temperature data is Remote Sensing

12 Systems, Inc. These brightness temperature data are gridded and distributed by NSIDC

13 (Maslanik and Stroeve, 1990).

The following procedure used daily SSMI polar stereographic grids with both a land mask and a sea surface temperature (SST) mask applied as described in Cavalieri et al. (1999). We also filtered out those days with no data or days with missing orbits (32 days out of 365) before undertaking the following steps.

First, F13 and F17 brightness temperature (TB) histograms for both hemispheres and for 22 each channel used in the NASA Team sea ice concentration algorithm $(19 \mathrm{H}, 19 \mathrm{~V}, 22 \mathrm{~V}$, and $37 \mathrm{~V}$, 23 standing for $19 \mathrm{GHz}$ horizontally polarized data, $19 \mathrm{GHz}$ vertically polarized data, etc.) were 
1 generated for the entire year of overlap (Figure 1). The histograms show that the minimum TBs

2 are nearly identical for F13 and F17 for all channels except 37V, where the F17 TBs are slightly

3 greater than those for F13. For each channel, we added approximately $5 \%$ of the full range of

4 TBs to the minimum TB to obtain a range of open water 'minimum' TBs. For the high TB or

5 sea ice end of the histogram, we subtracted approximately $10 \%$ of the range of TBs from the

6 maximum TB to obtain a range of sea ice 'maximum' TBs. Interestingly, all of the channels of

7 F13 exhibit a slightly greater maximum TB than F17, except for the 37V channel, which shows

8 almost identical maximum TBs (Figure 1). Next, we filtered each TB map, keeping only the

9 TBs in the minimum and maximum ranges and then obtained linear regression coefficients

10 (slope and intercept) between the F13 and F17 TBs for each day and channel.

11

12

13

14

15

16

17

18

19

20

21

22

Keeping only those regression coefficients within 1 standard deviation, we calculated a

yearly mean slope and intercept for each channel. Based on this mean slope and intercept, we computed the F17 sea ice algorithm tie-points for each hemisphere using the F13 tie-points as input. Finally, for the SH, we used the NH open water tie-points, because they were slightly lower, and we also used a different weather threshold for the F17 algorithm. The two weather filters used in the NT algorithm are based on the following spectral gradient ratios:

$$
\begin{aligned}
& \mathrm{GR}(37 / 19)=[\mathrm{TB}(22 \mathrm{~V})-\mathrm{TB}(19 \mathrm{~V})] /[\mathrm{TB}(22 \mathrm{~V})+\mathrm{TB}(19 \mathrm{~V})] \\
& \mathrm{GR}(22 / 19)=[\mathrm{TB}(37 \mathrm{~V})-\mathrm{TB}(19 \mathrm{~V})] /[\mathrm{TB}(37 \mathrm{~V})+\mathrm{TB}(19 \mathrm{~V})]
\end{aligned}
$$

Specifically, the thresholds used in the F17 SSMIS version of the NT sea ice algorithm are:

If $\mathrm{GR}(37 / 19)>0.05$ for locations in the $\mathrm{NH}$ or $>0.053$ for locations in the $\mathrm{SH}$, then the ice concentration is set to zero. 
1 If GR(22/19) $>0.045$ for locations in either hemisphere, then the ice concentration is set to zero.

2 These weather filters and their effectiveness are discussed in detail by Cavalieri et al. (1995).

3 The only change to the threshold values given in Cavalieri et al. (1995) is the 0.053 threshold

4 value for GR(37/19) for the SH. No other adjustments were made. Both the F13 and the F17

5 tie-points are presented in Table 1.

6

7

8

9

10

11

12

13

14

15

16

17

18

19

20

21

22

23

24

15

\section{Results}

Using the newly calculated F17 SSMIS tie-points (Table 1), Figure 2 presents plots of the daily percent difference between the F17 and F13 sea ice extents and areas for (a) the Northern Hemisphere (NH) and (b) the Southern Hemisphere (SH). The figure also gives the annual mean and standard deviation (SD) of the percent differences for each sea ice parameter and hemisphere. Scatter plots of F17 versus F13 sea ice extents and areas for both hemispheres (not shown) give r-squared values of 0.9998 or higher.

The annual mean percent difference \pm 1 SD between the F17 and F13 sea ice extents is $-0.0156 \% \pm 0.6204 \%$ and $0.0304 \% \pm 0.4880 \%$ for the $\mathrm{NH}$ and $\mathrm{SH}$, respectively. Both of these mean percent differences are within the corresponding mean differences $(0.05 \%)$ reported by Cavalieri et al. (1999) for the periods of sensor overlap in the 1978-1996 sea ice time series. For sea ice areas, the mean percent difference \pm 1 SD is $0.5433 \% \pm 0.3519 \%$ and $0.1550 \% \pm$ $0.3753 \%$ for the $\mathrm{NH}$ and $\mathrm{SH}$, respectively. These mean percent differences for sea ice area are within the mean sea ice area difference of $0.6 \%$ reported by Cavalieri et al. (1999) for the periods of sensor overlap in the 1978-1996 time series. 
The largest excursions from the zero percent difference line for both the NH and SH sea

2 ice extents occur during the summer months (Figure 2), when there are larger temporal changes

3 than during the winter months. The ascending node crossing times are different for F13 and F17,

4 and this difference may be particularly important during summer, when there is greater ice-edge

5 melt variability. The variations in sea ice area do not appear as large or as sudden as the

6 variations in sea ice extent, which is more susceptible to day-to-day weather forcing. This is also

7 reflected in the somewhat smaller sea ice area annual standard deviations.

8

\section{Conclusions}

The DMSP F17 SSMIS NASA Team sea ice concentration algorithm tie-points derived in this study result in a mean difference between the F13 SSMI and F17 SSMIS sea ice extents and areas of less than $0.031 \%$ and $0.6 \%$, respectively, for both hemispheres for the year of overlap, 2007. These mean differences are similar to those obtained previously when matching earlier sensors on different satellites in the generation of the current NASA GSFC sea ice time series (Cavalieri et al., 1999). The earlier intersensor calibrations were limited by the relatively short periods of sensor overlap of good data. These overlap periods were 22 days for the Nimbus 7 SMMR/DMSP F8 SSMI, 16 days for the DMSP F8/F11 SSMIs, and 5 months for the DMSP F11/F13 SSMIs. These overlap periods are in sharp contrast to the full year of overlap used for the F13/F17 intersensor calibration presented here. The much longer period of overlap in this study could account for why the agreements between the F13 and F17 sea ice extents and areas are not substantially better than the agreements obtained with the earlier sensor overlap periods, as there is more possibility for intersensor variability over a full year than over shorter periods 
1 (for example, winter versus summer). Furthermore, the level of agreement obtained previously

2 required subjective tuning of some of the tie-points (Cavalieri et al., 1999).

3

4 The DMSP F17 SSMI NASA Team sea ice concentration algorithm tie-points obtained in

5 this study will allow us to extend the NASA GSFC sea ice time series into the future for as long

6 as there are stable F17 SSMIS brightness temperatures available. Future sensors should be

7 planned to insure that there is at least one year of overlap between each pair of successive

8 SSMIS sensors.

9

10

11

12 The authors thank Dr. Walter Meier of the National Snow and Ice Data Center, Boulder,

13 Colorado, USA, for discussions regarding the selection of the DMSP SSMIS sensor to extend the

14 time series. We also thank the Cryosphere Program at NASA Headquarters for funding this

15 work and acknowledge receipt of the 2007 DMSP F17 SSMIS daily polar gridded brightness

16 temperatures from the National Snow and Ice Data Center, Boulder, Colorado, USA. 
1

2

3

4

5

7

8

9

10

11

12

13

14

15

16

17

18

19

20

21

22

23

24

2

15

9

4

\section{References}

D. Cavalieri, C. Parkinson, P. Gloersen, and H. J. Zwally, "Sea Ice Concentrations from Nimbus-

7 SMMR and DMSP SSM/I Passive Microwave Data", Boulder, Colorado USA: National Snow and Ice Data Center. Digital media, 1996, updated 2008.

D. J. Cavalieri, C. L. Parkinson, P. Gloersen, J. C. Comiso, and H. J. Zwally, "Deriving longterm time series of sea ice cover from satellite passive-microwave multisensor data sets", $J$. Geophys. Res. 104, 15,803-15,814, 1999.

D. J. Cavalieri, K. St. Germain, and C. T. Swift, "Reduction of weather effects in the calculation of sea ice concentration with the DMSP SSM/I", J. Glaciol., 41,455-464, 1995.

C. Derksen, A. Walker, E. LeDrew, B. Goodison, "Combining SMMR and SSM/I data for time series analysis of central North American snow water equivalent", J. Hydrometeor, 4, 304-316. doi: $10.1175 / 1525-7541(2003)$.

20 P. Gloersen, W. J. Campbell, D. J. Cavalieri, J. C. Comiso, C. L. Parkinson, H. J. Zwally, “A Arctic and Antarctic Sea Ice, 1978-1987: Satellite Passive Microwave Observations and Analysis",

22 National Aeronautics and Space Administration, Special Publication 511, Washington, D.C., pp.290, 1992. 
1 R. J. Gurney, J. L. Foster, and C. L. Parkinson, editors, “Atlas of Satellite Observations related

2 to Global Change," Cambridge University Press, Cambridge, United Kingdom, 470 pp, 1993.

3

4 M. D. King, C. L. Parkinson, K. C. Partington, and R. G. Williams, editors, "Our Changing

5 Planet: The View from Space", Cambridge University Press, Cambridge, United Kingdom, 391

6 pp., 2007.

7

8 D. B. Kunkee, G. A. Poe, D. J. Boucher, S. D. Swadley,Y. Hong, J. E. Wessel, and E. A. Uliana, 9 "Design and evaluation of the first Special Sensor Microwave Imager/Sounder", TGARS, 46, 4, $10 \quad 863-883,2008$.

11

12 J. Maslanik, and J. Stroeve, "DMSP SSM/I-SSMIS Daily Polar Gridded Brightness

13 Temperatures", Boulder, Colorado USA: National Snow and Ice Data Center. Digital media, 14 1990, updated 2010.

15

16 I. H. H. Zabel and K. C. Jezek, "Consistency in long-term observations of oceans and ice from 17 space", J. Geophys. Res., 99, C5, 10,109-10,120, 1994. 
4 southern $(\mathrm{SH})$ hemispheres.

5 Figure 2. Time series of the daily percent differences between F17 and F13 sea ice extents and 6 areas for 2007 based on the newly derived F17 sea ice tie-points (Table 1) for (a) the Northern 7 Hemisphere $(\mathrm{NH})$ and (b) the Southern Hemisphere $(\mathrm{SH})$. Percent differences are calculated as $8 \quad 100 \cdot(\mathrm{F} 17-\mathrm{F} 13) / \mathrm{F} 13$.

9 Table 1. F13 and F17 Tie-Points (TPs) for Open Water (OW), Northern Hemisphere First-Year 10 Ice (FYI) and Multiyear Ice (MYI), and Southern Hemisphere Ice Type A and Ice Type B. Ice 11 Type A has similar microwave characteristics to FYI in the Northern Hemisphere, but Ice Type 12 B is a different ice type than MYI, possibly FYI with a heavy snow cover; see Gloersen et al. 13 (1992) for further details. The F13 tie points are from Cavalieri et al. (1999), while the F17 tie 14 points are newly calculated as described in this paper. 

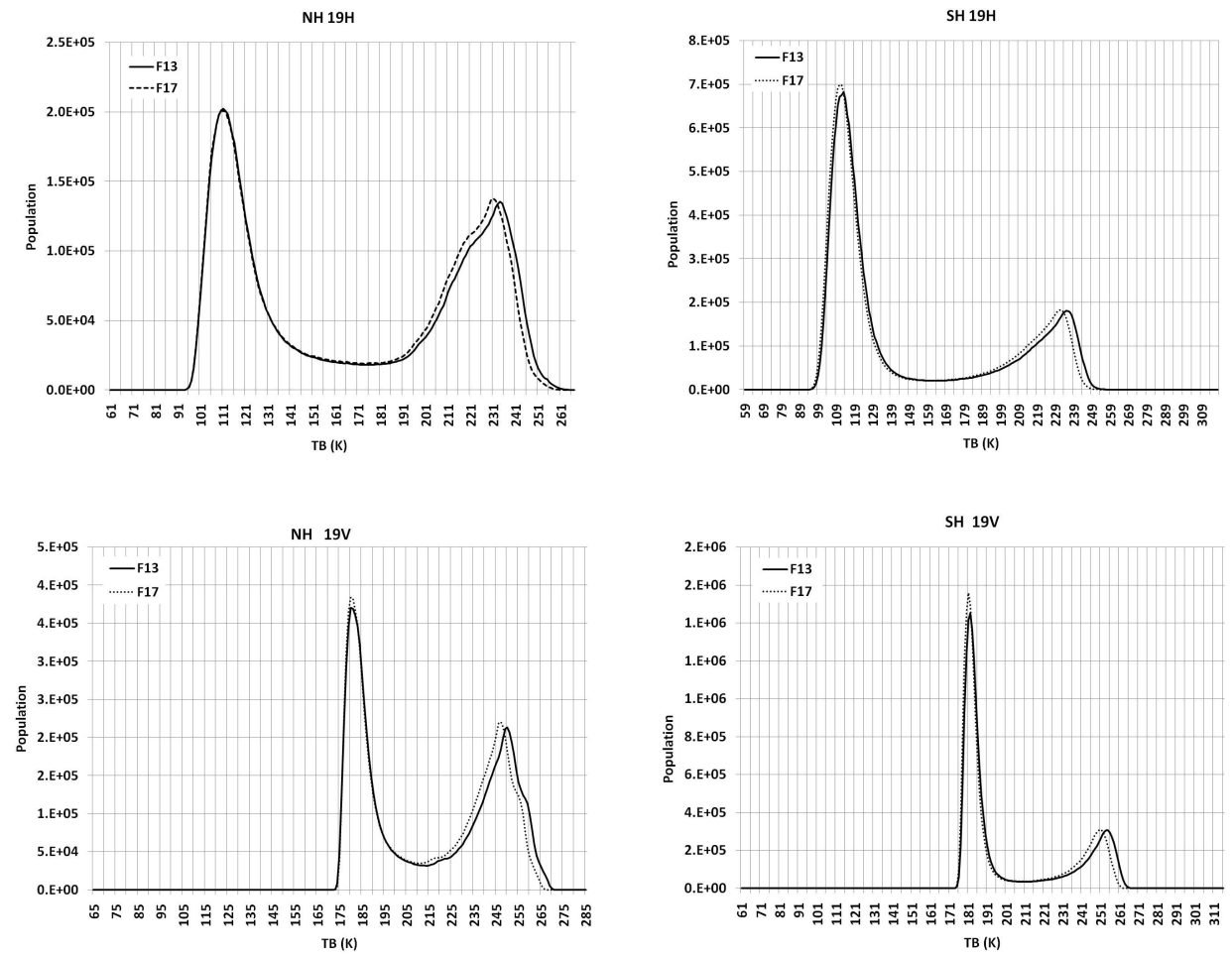

3
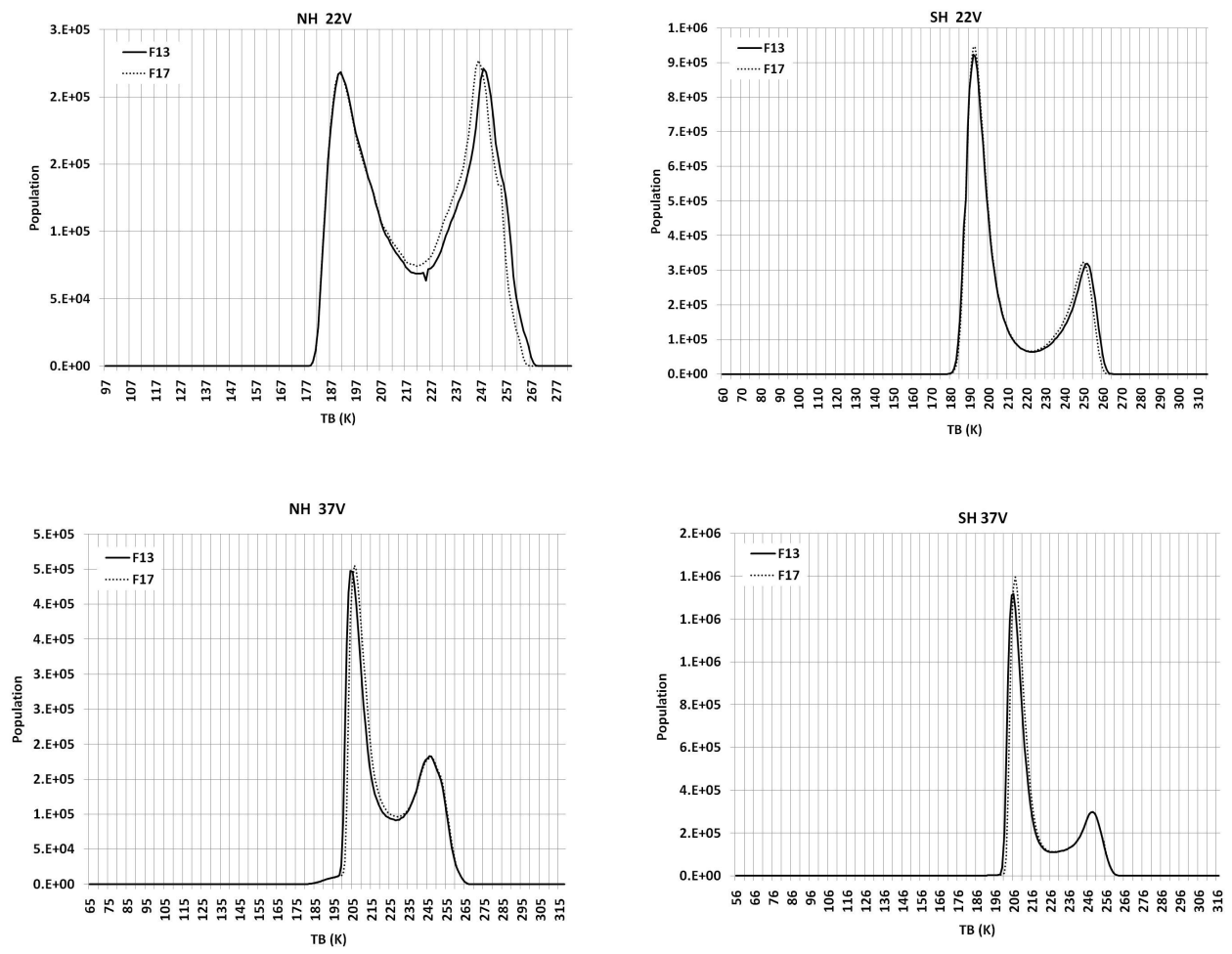
(a)
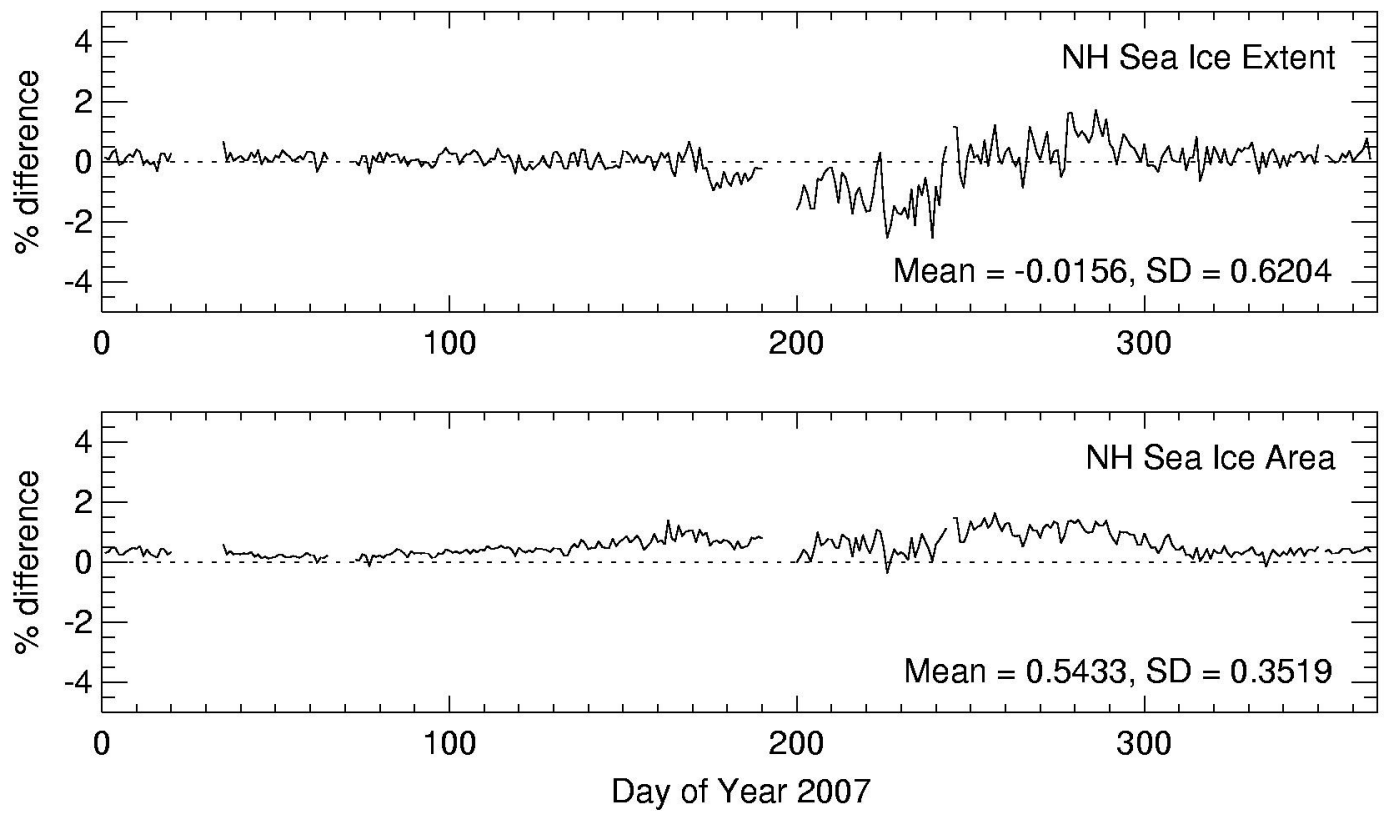

(b)
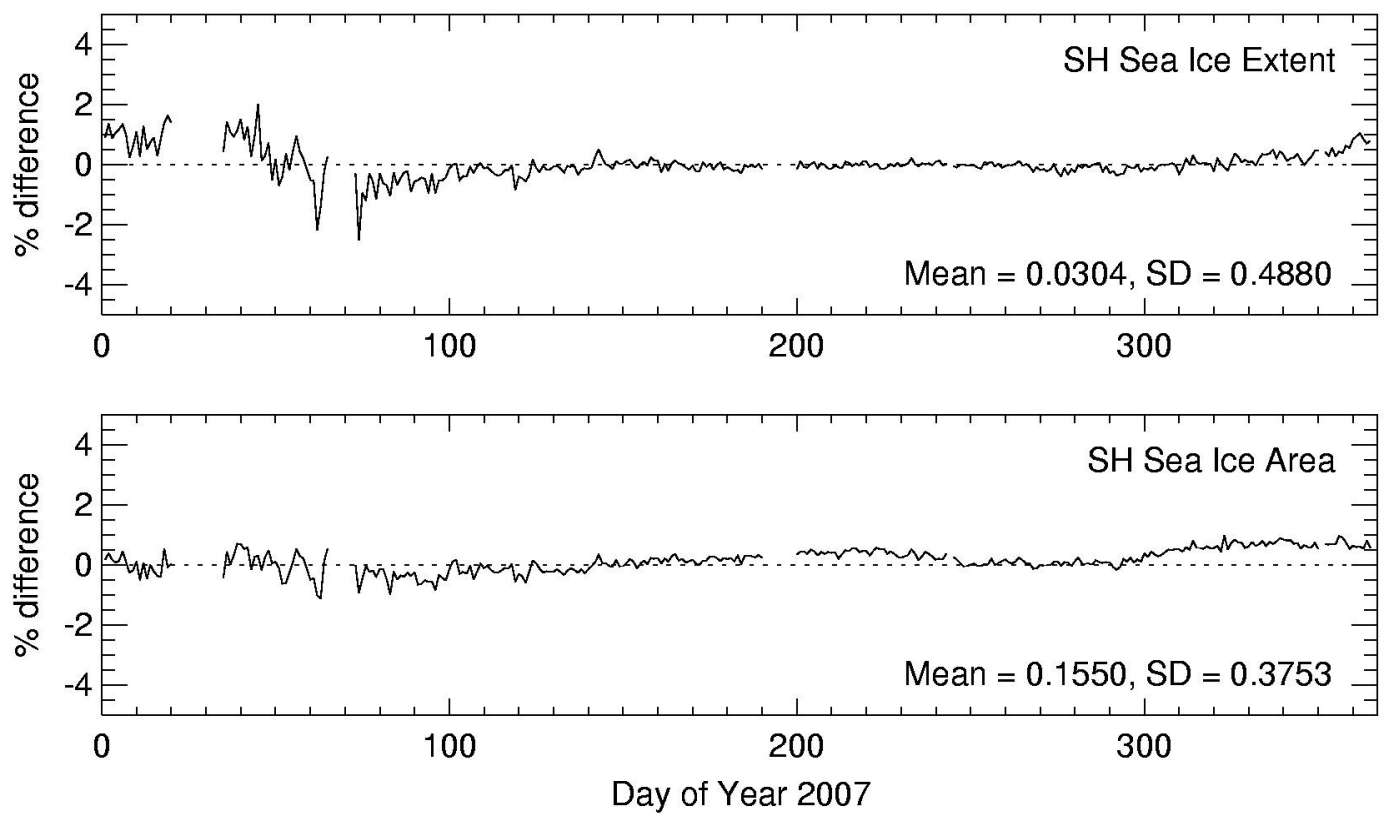

1

Figure 2 


\begin{tabular}{|c|c|c|c|c|c|}
\hline $\begin{array}{c}\text { Northern } \\
\text { Hemisphere }\end{array}$ & $\begin{array}{c}\text { F13 TP } \\
(\mathrm{K})\end{array}$ & $\begin{array}{c}\text { F17 TP } \\
(\mathrm{K})\end{array}$ & $\begin{array}{c}\text { Southern } \\
\text { Hemisphere }\end{array}$ & $\begin{array}{c}\text { F13 TP } \\
(\mathrm{K})\end{array}$ & $\begin{array}{c}\text { F17 TP } \\
\text { (K) }\end{array}$ \\
\hline 19V OW & 185.2 & 184.9 & 19V OW & 186.0 & 184.9 \\
\hline 19H OW & 114.4 & 113.4 & 19H OW & 117.0 & 113.4 \\
\hline 37V OW & 205.2 & 207.1 & 37V OW & 206.9 & 207.1 \\
\hline 19V FYI & 251.2 & 248.4 & 19V Ice Type A & 256.0 & 253.1 \\
\hline 19H FYI & 235.4 & 232.0 & 19H Ice Type A & 241.4 & 237.8 \\
\hline 37V FYI & 241.1 & 242.3 & 37V Ice Type A & 245.6 & 246.6 \\
\hline 19V MYI & 222.4 & 220.7 & 19V Ice Type B & 246.6 & 244.0 \\
\hline 19H MYI & 198.6 & 196.0 & 19H Ice Type B & 214.9 & 211.9 \\
\hline 37V MYI & 186.2 & 188.5 & 37V Ice Type B & 211.1 & 212.6 \\
\hline
\end{tabular}

Table 1 